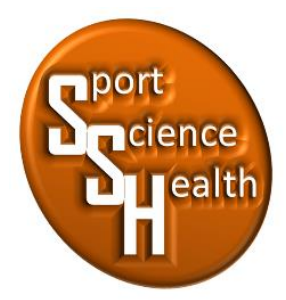

ISSN 2715-3886

\title{
Pengembangan Bahan Ajar Pencak silat Untuk Siswa Sekolah Dasar
}

\author{
Ricky Anugrah Akbar ${ }^{1 *}$, Eko Hariyanto ${ }^{2}$ \\ 1,2Jurusan Pendidikan Jasmani Kesehatan dan Rekreasi, Fakultas IImu Keolahragaan, \\ Universitas Negeri Malang, Jalan Semarang No. 5, Malang, Jawa Timur, 65145, Indonesia \\ *Penulis koresponden: Rickydhea9@gmail. com, 081335582470
}

\begin{abstract}
Learning physical education, sports, and health in elementary schools in accordance with ideal conditions must include: (1) spiritual attitude competencies, (2) social attitudes, (3) knowledge, and (4) skills. The subject matter which covers the core of the curriculum objectives includes martial arts. Martial arts learning material is contained in KD 3. 4 to understand the specific movements of the martial arts, and KD 4.4 to act on the specific movements of the martial arts. If referring to the applicable curriculum products, this self-defense material must be taught in physical education, sports and health learning. However, the real conditions in the field, especially in Kepanjen sub-district, not all elementary schools teach martial arts in their learning, only a few schools teach it. The reason is the lack of teaching materials and the lack of learning media presented. The use of interactive teaching materials in learning physical education, sports, and health in elementary schools is a solution to help educators and students understand pencak silat material in the learning process.
\end{abstract}

Keyword: development, teaching materials, pencak silat, elementary students

\begin{abstract}
Abstrak: Pembelajaran pendidikan jasmani, olahraga, dan kesehatan di sekolah dasar sesuai dengan kondisi idealnya harus mencangkup: (1) kompetensi sikap spiritual, (2) sikap sosial , (3) pengetahuan , dan (4) keterampilan. Materi pelajaran yang mencangkup inti dari tujuan kurikulum tersebut antara lain ilmu beladiri. Materi pembelajaran ilmu beladiri tertuang pada KD 3. 4 memahami gerak spesifik seni beladiri, dan KD 4.4 memperaktikan gerak spesifik seni beladiri. Jika mengacu pada prodesur kurikulum yang berlaku, materi beladiri ini wajib diajarkan dalam pembelajaran pendidikan jasmani, olahraga, dan kesehatan. Namun kondisi nyata di lapangan khususnya di kecamatan Kepanjen tidak semua sekolah dasar mengajarkan ilmu beladiri pencak silat di pembelajarannya, hanya beberapa sekolah yang mangajarkannya. Penyebabnya adalah kurang nya bahan ajar dan ketidak menarikan media pembelajaran yang disajikan. Penggunaan bahan ajar yang interaktif dalam pembelajaran pendidikan jasmani, olahraga, dan kesehatan di sekolah dasar menjadi solusi untuk membantu pendidik dan peserta didik memahami materi pencak silat dalam proses pembelajaran.
\end{abstract}

Kata kunci: pengembangan, bahan ajar, pencak silat, siswa SD

\section{PENDAHULUAN}

Pendidikan mempunyai peranan yang sangat penting bagi pengembangan sumber daya manusia, hal tersebut tertuang dalam tujuan pendidikan nasional kita (UU N. 20 Tahun 2003) yang dinyatakan bahwa tujuan pendidikan nasional adalah untuk mengembangkan manusia Indonesia dan mencerdaskan kehidupan bangsa, manusia yang mempunyai takwa dan iman kepada Tuhan Yang Maha Esa dan mempunyai budi pekerti yang luhur, mandiri, kepribadian yang mantap, kesehatan rohani, dan jasmani, keterampilan dan 
pengetahuan, dan mempunyai rasa tanggung jawab untuk berbangsa dan bemasyarakat (Adi \& Fathoni, 2019). Maknanya adalah setiap individu manusia mempunyai hak dan kewajiban untuk berkembang sesuai dengan kemampuan yang dimilikinya(Fathoni, 2018). Untuk mewujudkan dan mencapai tujuan tersebut maka di dunia pendidikan disusunlah sebuah pedoman yang dalam dunia pendidikan dikenal dengan istilah kurikulum (Adi \& Fathoni, 2020). Kurikulum pendidikan dilaksanakan dihampir semua lembaga pendidikan mulai dari Sekolah Dasar/MIN, Sekolah Menengah Pertama/MTs, serta Sekolah Menengah Atas/MAN. Dan salah satu mata pelajaran yang harus dilaksanakan dilembaga pendidikan adalah mata pelajaran pendidikan jasmani, olahraga dan kesehatan.

Pelaksanaan proses pembelajaran akan sangat menentukan kualitas kemampuan setiap individu peserta didik, untuk itu peran seorang pendidik sangat dibutuhkan kualitasnya dalam memberikan materi pelajaran dan informasi kepada peserta didik agar dalam pembelajaran tercipta suasana yang menyenangkan, menarik, serta kondisi yang kondusif. Untuk tercapai hal tersebut, maka proses pembelajaran harus diarahkan lebih berpusat kepada peserta didik dengan menyediakan komponen-komponen belajar yang mandiri serta terbaru dalam mengikuti perkembangan jaman. Menurut Dwiyogo (2018) Berdasarkan beberapa hasil penelitian menunjukkan bahwa penggunaan bahan ajar dapat memberikan sumbangan yang positif dalam proses pembelajaran. Seperti hasil penelitian yang dilakukan oleh Purwaningtyas \& Hariyadi (2017) yang menyatakan bahwa dengan adanya bahan ajar dalam proses pembelajaran dapat membuat proses pembelajaran lebih efektif dan efisien, dan bahan ajar mempunyai potensi untuk menjebatani antara pengajar dan peserta didik Di dalam bahan ajar yang baik harus terdapat sumber-sumber belajar yang sesuai dengan tujuan pencapaian hasil belajar, bahan ajar bisa berupa, buku teks, modul, LKS, audio, video dan interaktif. Asngari (2019) yang menyatakan bahwa bahan ajar merupakan strategi yang digunakan sebagai sumber informasi yang paling mudah didapat oleh peserta didik untuk mempraktekkan materi dalam pembelajaran, agar dapat mencapai target dari kurikulum yang digunakan

\section{Kebugaran Jasmani}

Pendidikan jasmani merupakan kesatuan dari pendidikan secara menyeluruh yang sangat menunjang dari tujuan pendidikan nasional. Pada dasarnya pendidikan jasmani merupakan salah satu mata pelajaran wajib yang harus dilaksanakan di lembaga pendidikan baik di Sekolah dasar/MIN, Sekolah Menengah Pertama/MTs, dan Sekolah Menengah Atas/MAN. Sari \& Nurrochmah (2019) menyatakan pendidikan jasmani sebagai fase dari total proses pendidikan yang membantu dalam mewujudkan program pendidikan fisik yang efektif membentuk siswa untuk memahami dan menghargai nilai kebaikan sebagai alat untuk mencapai produktivitas, keefektifan, dan kebahagian terbesar mereka sebagai individu. Menurut Rahman, Kurniawan, \& Heynoek (2020) pendidikan jasmani dapat diartikan sebagai proses pendidikan melalui kegiatan fisik yang tujuannya adalah pengembangan individu melalui pengalaman gerak. Selanjutkan dikatakan oleh Junaedi (2016) pendidikan jasmani merupakan komponen utama yang terikat dengan pendidikan secara utuh dan merupakan komponen untuk mewujudkan tujuan pendidikan nasional.

\section{Bahan Ajar}

Bahan ajar memiliki peran dan fungsi yang sangat strategis. bagi proses pembelajaran yang dapat membantu guru dan siswa dalam kegiatan pembelajaran. Bahan ajar dapat menggantikan sebagian peran guru dan mendukung pembelajaran individual, dan juga dapat memberikan dampak positif bagi guru, karena sebagian waktunya dapat dicurahkan untuk membimbing belajar siswa. Sedangkan dampak positifnya bagi siswa adalah dapat mengurangi ketergantungan pada guru dan dapat membiasakan belajar mandiri. Menurut Tegeh \& Kirna (2013) pengertian bahan ajar adalah segala bentuk bahan yang digunakan untuk membantu guru dalam melaksanakan kegiatan belajar mengajar. Bahan yang dimaksud bisa berupa bahan tertulis maupun bahan tidak tertulis. Arsanti (2018) bahan ajar adalah bagian sumber belajar yang berisi informasi pembelajaran, baik bersifat terbatas ataupun bersifat luas yang dapat digunakan sebagai keperluan belajar mengajar.

\section{Pencak Silat}

Wahyu Putra \& Siswantoyo (2019) berpendapat bahwa bukti adanya seni bela diri bisa dilihat dari berbagai artefak senjata yang ditemukan dari masa klasik (Hindu-Budha) serta pada pahatan relief-relief yang berisikan sikap-sikap kuda-kuda silat di candi Prambanan dan Borobudur. Dalam bukunya, Draeger menuliskan bahwa senjata dan seni beladiri silat adalah tak terpisahkan, bukan hanya dalam olah tubuh saja, melainkan juga pada hubungan spiritual yang terkait erat dengan kebudayaan Indonesia. Sementara itu Sheikh Shamsuddin 
(2005) berpendapat bahwa terdapat pengaruh ilmu bela diri dari Cina dan India dalam silat. Hal ini karena sejak awal kebudayaan Melayu telah mendapat pengaruh dari kebudayaan yang dibawa oleh pedagang maupun perantau dari India, Cina, dan mancanegara lainnya. Gerak dasar pencak silat adalah suatu gerakan terencana, terarah, terkoordinasi, dan terkendali, yang mempunyai empat aspek sebagai satu kesatuan yakni aspek mental spiritual, aspek bela diri, aspek olahraga, dan aspek seni budaya.

\section{METODE}

Langkah-langkah dalam penelitian dan pengembangan yang bertujuan untuk mengembangkan bahan ajar Pencak Silat bentuk buku dan video di Sekolah Dasar se kecamatan Kepanjen ini menggunakan enam langkah dengan prosedur pengembangan sebagai berikut: (1) Penelitian dan pengumpulan data dalam melakukan penelitian awal atau analisis kebutuhan (need assessment) dengan cara wawancara kepada Guru Pendidikan Jasmani, Olahraga dan Kesehatan dan penyebaran angket kepada siswa Sekolah Dasar, (2) Menganalisis kesesuaian produk pengembangan bahan ajar mata pelajaran pencak silat yang dikemas dalam bentuk Buku dan v. ideo, (3) Melaksanakan desain rancangan produk terkait dengan pengemasan yang menggunakan multimedia interaktif, hal ini terkait dengan apa saja yang akan dimasukkan kedalam lay out tampilan multimedia interaktif. (4) Mengembangkan bahan ajar bentuk buku, gambar dan video yang nantinya akan dikemas dalam bentuk multimedia interaktif. (5) Evaluasi Ahli dilakukan kepada ahli pencak silat, ahli pembelajaran pencak silat dan ahli media untuk memperoleh masukan tentang produk yang sudah dikembangkan. (6) Pelaksanaan pengujian produk dilapangan dengan melibatkan siswa sekolah dasar se kecamatan Kepanjen menggunakan 10 subjek diambil secara acak/random sampling) untuk skala kecil dan menggunakan 30 siswa diambil dengan teknik random sampling untuk skala besar. (7) Evaluasi produk dan penyempurnaan produk hasil uji lapangan utama (revisi produk berdasarkan saran-saran dari hasil uji coba lapangan utama). (8) Tahapan pengembangan produk dimodifikasi oleh peneliti sebagaimana tahapan rancangan tersebut disesuaikan dengan langkah pengembangan produk yang paling tepat dan efektif untuk merancang produk sehingga skema pengembangan disusun dalam bagus (Cain, 2014; Jamshed, 2014; Walenta, 2019).

\section{Desain Penelitian}

Model pengembangan yang digunakan di dalam penelitian ini mengacu pada model pengembangan Lee\&Owens (2004:93), dengan langkah-langkah pengembangan sebagai berikut:(1) Melakukan Need Assessment atau analisis kebutuhan (2) Melakukan Front-end analysis atau analisis awal dan akhir (3) Melakukan Design atau desain produk. (4) Development atau pengembangan produk (5) Implementation atau pelaksanaan. (6) Evaluation atau evaluasi produk.

\section{HASIL}

\section{Hasil Analisis Ahli Pembelajaran}

Data Analisis validasi produk yang dilakukan oleh ahli pembelajaran pendidikan jasmani dan kesehatan disajikan pada Tabel 1 berikut ini

Tabel 1 Data Hasil Analisis Validasi Ahli Pembelajaran

\begin{tabular}{lllllll}
\hline Komponen & $\begin{array}{l}\text { Skor } \\
\text { Min }\end{array}$ & $\begin{array}{l}\text { Skor } \\
\text { Max }\end{array}$ & $\begin{array}{l}\text { Skor } \\
\text { Hasil }\end{array}$ & $\begin{array}{c}\text { Presentase } \\
(\%)\end{array}$ & Keterangan \\
\hline 1 & Kejelasan & 16 & $\mathbf{6 4}$ & 58 & $90,62 \%$ & Sangat Valid \\
2 & Ketepatan & 3 & $\mathbf{1 2}$ & 11 & $91,66 \%$ & Sangat Valid \\
3 & Kesesuaian & 2 & $\mathbf{8}$ & 8 & $100 \%$ & Sangat Valid \\
4 & Kemudahan & 2 & $\mathbf{8}$ & 8 & $100 \%$ & Sangat Valid \\
5 & Kemenarikan & 2 & $\mathbf{8}$ & 8 & $100 \%$ & Sangat Valid \\
& Rata-rata & 25 & $\mathbf{1 0 0}$ & 93 & $93 \%$ & Sangat Valid \\
& Keseluruhan & & & & & \\
\hline
\end{tabular}

Berdasarkan Tabel 1 yang terdapat lima komponen penilaian, dengan rincian hasil sebagai berikut: komponen kejelasan dengan hasil $(90,62 \%)$ dapat dinyatakan sangat valid komponen ketepatan didapat hasil $(91,66 \%)$ 
sangat valid, komponen kesesuaian didapat hasil (100\%) sangat valid, komponen kemudahan didapat hasil $(100 \%)$ sangat valid, komponen kemenarikan didapat hasil (100\%) sangat valid. Kemudian untuk rata-rata keseluruhan data analisis ahli pembelajaran dengan hasil (93\%). Berdasarkan hasil yang diperoleh dari validasi ahli pembelajaran, maka produk dapat dilanjutkan ke tahap uji coba.

\section{Hasil Data Analisis Validasi Ahli Media}

Hasil analisis validasi ahli media akan disajikan dalam Tabel 2 sebagai berikut ini.

Tabel 2 Data Hasil Analisis Validasi Ahli Media

\begin{tabular}{lllllll}
\hline No & Komponen & $\begin{array}{l}\text { Skor } \\
\text { Min }\end{array}$ & $\begin{array}{l}\text { Skor } \\
\text { Max }\end{array}$ & $\begin{array}{c}\text { Skor } \\
\text { Hasil }\end{array}$ & $\begin{array}{c}\text { Presentase } \\
(\%)\end{array}$ & Keterangan \\
\hline 1 & Teks & 8 & 32 & 32 & $100 \%$ & Sangat Valid \\
2 & Gambar/Foto & 9 & 36 & 33 & $91,66 \%$ & Sangat Valid \\
3 & Audio/Suara & 5 & 20 & 19 & $95 \%$ & Sangat Valid \\
4 & Video & 3 & 12 & 11 & $91,66 \%$ & Sangat Valid \\
5 & Desain/Tampilan & 4 & 16 & 15 & $93,75 \%$ & Sangat Valid \\
& Rata-rata & 29 & 116 & 110 & $94,82 \%$ & Sangat Valid \\
& Keseluruhan & & & & & \\
\hline
\end{tabular}

Sesuai Tabel 2 di mana terdapat 5 komponen penilaian, dengan hasil yaitu: komponen teks didapat hasil $(100 \%)$ sangat valid, komponen gambar/foto dengan hasil $(91,66 \%)$ dapat dinyatakan sangat valid. Komponen Audio/suara didapat hasil (95\%) dinyatakan sangat valid, komponen video didapat hasil (91, 66\%) dapat dinyatakan sangat valid, dan komponen desain/tampilan didapat hasil (93,75\%) dapat dinyatakan sangat valid. Rata-rata keseluruhan data dari ahli media mendapat hasil $(94,82 \%)$. Sesuai hasil yang diperoleh dari validasi ahli media, produk yang dihasilkan dapat dilanjutkan ke tahap uji coba.

\section{Data Analisis Validasi Materi a Pencak Silat}

Tabel 3 Data Hasil Analisis Validasi Ahli Materi Pencak Silat

\begin{tabular}{lllllll}
\hline No & Komponen & $\begin{array}{l}\text { Skor } \\
\text { Min }\end{array}$ & $\begin{array}{l}\text { Skor } \\
\text { Max }\end{array}$ & $\begin{array}{l}\text { Skor } \\
\text { Hasil }\end{array}$ & $\begin{array}{c}\text { Presentase } \\
(\%)\end{array}$ & Keterangan \\
\cline { 2 - 7 } 1 & Kejelasan & 17 & $\mathbf{6 8}$ & 66 & $97,05 \%$ & Sangat Valid \\
2 & Ketepatan & 3 & $\mathbf{1 2}$ & 11 & $91,66 \%$ & Sangat Valid \\
3 & Kesesuaian & 2 & $\mathbf{8}$ & 8 & $100 \%$ & Sangat Valid \\
4 & Kemudahan & 2 & $\mathbf{8}$ & 8 & $100 \%$ & Sangat Valid \\
5 & Kemenarikan & 7 & $\mathbf{2 8}$ & 28 & $100 \%$ & Sangat Valid \\
& Rata-rata & 31 & $\mathbf{1 2 4}$ & 121 & $97,58 \%$ & Sa ngat Valid \\
& Keseluruhan & & & & & \\
\hline
\end{tabular}

Berdasarkan Tabel 4. 3 mendapatkan hasil sebagai berikut: (1) kejelasan materi didapat haasil (97,05\%) yaitu sangat valid, (2) ketepatan materi dengan hsil (91,66\%) sangat valid, (3) kesesuaian materi didapat hasil (100\%) sangat valid , (4) kemudahan materi dengan hasil (100\%) dinyatakan sangat valid, (5) dan kemenarikan materi didapat hasil $(100 \%)$ dinyatakan sangat valid. Total keseluruhan data analisis ahli materi pencak silat dengan presentase sebesar (93\%). Untuk itu produk yang buat bisa dilanjutkan le tahap uji coba.

\section{Hasil Analisis Uji Kelompok Kecil}

Berdasarkan hasil analisis data yang dilakukan pada kelompok kecil yang selanjutnya akan disajikan dalam Tabel 4 berikut ini. 
Tabel 4 Data Hasil Uji Coba Kelompok Kecil

\begin{tabular}{llllll}
\hline No & Komponen & $\begin{array}{l}\text { Skor } \\
\text { Min }\end{array}$ & $\begin{array}{l}\text { Skor } \\
\text { Max }\end{array}$ & $\begin{array}{l}\text { Skor } \\
\text { Hasil }\end{array}$ & $\begin{array}{c}\text { Presentase } \\
(\%)\end{array}$ \\
\hline 1 & Kemenarikan & 85 & $\mathbf{3 4 0}$ & 300 & $88,23 \%$ \\
2 & Kemudahan & 34 & $\mathbf{1 3 6}$ & 116 & $85,29 \%$ \\
3 & Kejelasan & 68 & $\mathbf{2 7 2}$ & 237 & $87,13 \%$ \\
4 & Keefektifan & 34 & $\mathbf{1 3 6}$ & 115 & $84,55 \%$ \\
& Rata-rata Keseluruhan & 221 & $\mathbf{8 8 4}$ & 768 & $86,87 \%$ \\
\hline
\end{tabular}

Berdasarkan Tabel 4 terdapat perolehan hasil dari 4 komponen yaitu kemenarikan produk $(88,23 \%)$ dengan criteria sangat valid , kemudahan produk $(85,29 \%)$ kriteria sangat valid, kejelasan produkn $(87,13 \%)$ dengan kreteria sangat valid, keefektifan produk $(84,55 \%)$ criteria sangat valid dan total rata-rata keseluruhan mendapatkan hasil presentase $(86,87 \%)$ dengan kriteria sangat valid. Apabila dikonversi ke Tabel 3. 2 penggolongan pengolahan data presentase mulai dari $81,01 \%-100 \%$ masuk kategori dengan keterangan dapat digunakan tanpa revisi maka hasil tersebut telah memenuhi kelayakan, sehingga produk Pengembangan bahan ajar pencak silat untuk siswa Sekolah Dasar (SD) masuk kategori sangat valid kemudian bisa dilanjutkan ke tahap selanjutnya pada uji coba kelompok besar.

\section{Hasil Analisis Uji Coba Kelompok Besar}

Berdasarkan hasil analisis data yang dilakukan pada kelompok kecil yang selanjutnya akan disajikan dalam Tabel 5 berikut ini.

Tabel 5 Data Hasil Uji Coba Kelompok Kecil

\begin{tabular}{llllll}
\hline No & Komponen & $\begin{array}{l}\text { Skor } \\
\text { Min }\end{array}$ & $\begin{array}{l}\text { Skor } \\
\text { Max }\end{array}$ & $\begin{array}{l}\text { Skor } \\
\text { Hasil }\end{array}$ & $\begin{array}{c}\text { Presentase } \\
(\%)\end{array}$ \\
\hline 1 & Kemenarikan & 284 & $\mathbf{1 1 3 6}$ & $\mathbf{9 8 5}$ & $86,71 \%$ \\
2 & Kemudahan & 213 & $\mathbf{8 5 2}$ & 702 & $82,39 \%$ \\
3 & Kejelasan & 284 & $\mathbf{1 1 3 6}$ & 981 & $86,35 \%$ \\
4 & Keefektifan & 142 & $\mathbf{5 6 8}$ & 486 & $85,56 \%$ \\
& Rata-rata Keseluruhan & 923 & $\mathbf{3 6 9 2}$ & 3154 & $85,42 \%$ \\
\hline
\end{tabular}

Berdasakan Tabel 4.5 terdapat perolehan hasil dari 4 komponen yaitu kemenarikan produk $(86,71 \%)$ dengan criteria sangat valid, , kemudahan produk (82, 39\%) dengan criteria sangat valid, kejelasan produk (86, 35\%) dengn criteria sangat valid, keefektifan produk $(85,56 \%)$ criteria sangat valid, dan total rata-rata keseluruhan mendapatkan hasil presentase $(85,42 \%)$ dengan criteria sangat valid. Apabila dikonversikan Tabel 3. 2 penggolongan pengolahan data presentasae maka hasil tersebut telah memenuhi kelayakan, sehingga produk bahan ajar pencak silat pada pembelajaran pendidikan jasmani, olahraga dan kesehatan (PJOK) masuk kategori sangat valid. Berdasarkan uji coba kelompok besar memperoleh hasil $(85,42 \%)$ dan uji coba kelompok kecil $(86,87 \%)$. Dapat di tarik kesimpulan berdasarkan Tabel 3.2 pengolhan data presentase mulai $81.00 \%-100 \%$ masuk kategori sangat valid dengan keterangan dapat digunakan tanpa revisi, sehingga produk pengembangan bahan ajar pencak silat dapat di terapkan pada proses pembelajaran untuk siswa sekoah dasar (SD).

\section{PEMBAHASAN}

Meskipun hasil yang didapatkan baik dan layak digunakan dari produk pengembangan bahan ajar pencak silat untuk siswa Sekolah Dasar (SD) ada bebearapa point perlu diperhatikan sebelum melakukan pengembangan produk lebih lanjut, (1) acuan dasar dari pengembangan produk ini adalah hasil analisis kebutuhan atau kondisi pada saat sekarang apabila pengembang selanjutnya ingin mengembangkan produk dengan konteks sejenis atau lainya agar memperhatikan kembali kondisi pada saat itu, (2) sebelum mengembangkan produk seharusnya memperhatikan materi yang akan diuji cobakan agar produk yang dihasilkan tepat ke sasaran (3) penelitian dan pengembangan dengan bahan perlu memperhatikan isi dari bahan ajar dari kompetensi, kemampuan pendidik, tujuan pembelajaran, kurikulum yang dipakai rujukan, tempat, serta kesedian sumber daya pendukung pembelajaran tatap muka. Berdasarkan saran saran yang telah dijelaskan dapat disimpulkan 
bahwa pembelajaran tatap muka lebih mengefesiensikan waktu pada pembelajaran tatap muka bisa dilanjutkan dengan pembelajaran offline yang menggunakan multimedia interaktif dengan tampilan berbeda dan menarik dapat meningkatkan semangat dan motivasi peserta didik selama mengikuti proses pembelajaran.

\section{KESIMPULAN}

Dari hasil keseluruhan penelitian ini yang mana menerapakan model pembelajaran tatap muka berupa buku cetak, dan offline menggunakan multimedia interaktif memberikan hasil belajar yang efektif melalui multimedia interaktif yang berkembang saat ini pada lingkungan belajar. Berdasarkan hasil penelitian diatas yang dipaparkan diatas maka dapat disimpulkan bawah bahan ajar dapat meningkatkan motivasi minat, serta hasil belajar siswa dalam pembelajaran pendidikan jasmani, olahraga, dan kesehatan (PJOK) yang mencangkup efektivitas, efiensi, dan daya tarik pembelajaran.

\section{DAFTAR PUSTAKA}

Adi, S., \& Fathoni, A. F. (2019). Development of Learning Model Based on Blended Learning in Sports School. https://doi.org/10.2991/acpes-19.2019.2

Adi, S., \& Fathoni, A. F. (2020). The effectiveness and efficiency of blended learning at sport schools in Indonesia. International Journal of Innovation, Creativity and Change.

Arsanti, M. (2018). Pengembangan Bahan Ajar Mata Kuliah Penulisan Kreatif Bermuatan Nilai-Nilai Pendidikan Karakter Religius Bagi Mahasiswa Prodi PBSI, FKIP, UNISSULA. kredo: Jurnal IImiah Bahasa Dan Sastra. https://doi.org/10.24176/kredo.v1i2.2107

Asngari, H. (2019). Pengembangan Bahan Ajar Berbasis Kompetensi. Jurnal Kebijakan Dan Pengembangan Pendidikan (JKPP).

Cain, T. (2014). The Sage handbook of action research: participative inquiry and practice. International Journal of Research \& Method in Education. https://doi.org/10.1080/1743727x.2014.937521

Dwiyogo, W. (2018). Developing a Blended Learning-Based Method for Problem-Solving in Capability Learning. Tojet - The Turkish Online Journal of Educational Technology.

Fathoni, A. F. (2018). The Role of Blended Learning on Cognitive Step in Education of Sport Teaching by Adjusting the Learning Style of the Students. https://doi.org/10.2991/isphe-18.2018.49

Jamshed, S. (2014). Qualitative research method-interviewing and observation. Journal of Basic and Clinical Pharmacy. https://doi.org/10.4103/0976-0105.141942

Junaedi, A. (2016). Survei Tingkat Kemajuan Pendidikan Jasmani, Olahraga, Dan Kesehatan Di Sma, Smk, Dan Ma Negeri Se-Kabupaten Gresik. Jurnal Pendidikan Olahraga Dan Kesehatan.

Purwaningtyas, W. D. D., \& Hariyadi, I. (2017). Pengembangan Modul Elektronik Berbasis Online Dengan Program Edmodo. Jurnal Pendidikan. https://doi.org/http://dx.doi.org/10.17977/jp.v2i1.8471

Rahman, Z. (Universitas N. M., Kurniawan, A. W. (Universitas N. M., \& Heynoek, F. P. (Universitas N. M. (2020). Pengembangan Pembelajaran Kebugaran Jasmani Unsur Kecepatan Berbasis Multimedia Interaktif. Sport Science and Health, 2(1), 78-92. Retrieved from http://journal2.um.ac.id/index.php/jfik/article/view/11692/5123

Sari, D. A. (Universitas N. M., \& Nurrochmah, S. U. N. M. (2019). Survei Tingkat Kebugaran Jasmani di Sekolah Menengah Pertama. Sport Science and Health, 1(2), 132-138. Retrieved from http://journal2.um.ac.id/index.php/jfik/article/view/10633/4796

Tegeh, I. M., \& Kirna, I. M. (2013). Pengembangan Bahan Ajar Metode Penelitian Pendidikan Dengan Addie Model. Jurnal lka.

Wahyu Putra, F., \& Siswantoyo, M. (2019). The History of Pencak Silat Goes to the World in the Period of 1980-2000. https://doi.org/10.2991/yishpess-cois-18.2018.71 
Walenta, M. (2019). Research method. In Second Language Learning and Teaching. https://doi.org/10.1007/978-3-030-04699-6_4 